neuropathy and plasma glucose control. Am J Med 1981;70: 195-200.

55 Pietri A, Ehle AL, Raskin P. Changes in nerve conduction velocity after six weeks of glucoregulation with portable insulin infusion pumps. Diabetes 1980;29:668-71.

56 Handelsman DJ, Turtle JR. Clinical trial of an adiose reductase inhibitor in diabetic neuropathy. Diabetes 1981;30:459-464.

57 Fagius J, Jameson S. Effects of aldose reductase inhibitor treatment in diabetic polyneuropathy - a clinical and neurophysiological study. J Neurol Neurosurg Psychiatry 1981;44:
991-1001.

58 Gabbay KH, Speck N, Loo S, Hirsch HJ, Ackil AA. Aldose reductase inhibition: studies with Alrestatin. Metabolism 1979; 28:Suppl 1:471-6.

59 Culebras A, Alio J, Herrera JL, Lopez-Fraile IP. Effect of an aldose reductase inhibitor on diabetic peripheral neuropathy: preliminary report. Arch Neurol 1981;38:133-4.

60 Judzewitsch RG, Jaspan JB, Polonsky KS, et al. Aldose reductase inhibition improves nerve conduction velocity in diabetic patients. N Engl J Med 1983;308:119-25.

\title{
Some remarks on the work of Andrew Connal: A study of cerebrospinal fluid in meningitis
}

"In a series of investigations based upon the examination of cerebrospinal fluid flowing spontaneously from the nose of a girl with a tumour of the brain, and numerous other cases, as meningitis and so on, I found-mercury, iodides, and salicylates given by the mouth, cutaneously or subcutaneously, do not pass into the cerebrospinal fluid, as I showed conclusively in a series of exact experiments, and this fact is of fundamental importance as regards the whole subject of the absorption process in the brain."

v Jaksch, R. Q J Med 1909-10;3:296.

\section{The importance of optic neuritis and retinal haemorrhages in the diagnosis of chronic septic endocarditis}

RT ROSS

"In the acute cases, especially those of puerperal origin, and in the more or less acute cases complicating with suppurative meningitis and cerebral abscess, panophthalmitis, embolism of the central artery of the retina, optic neuritis, and the retinitis septica of von Roth, have been frequently met with, but in the literature at my command $I$ have been able to find few references to the occurrence of double optic neuritis (papilloedema), apparently a toxaemic manifestation, comparatively early in the history of the chronic form of the disease."

Falconer, AW. Q J Med 1909-10;3:107-14.

RT ROSS

The respiratory movements in hemiplegia

"In ordinary breathing the following peculiarities are observed on the paralyzed side.

1. The respiratory excursion both inspiratory and expiratory is much diminished, ie the height of the wave is reduced.

2. The character of the wave is altered.
(a) It is much rounder.
(b) It is delayed, for the rise may not begin until that on the sound side is $3 / 4$ to $5 / 6$ complete.
(c) It is shorter, so that the post-expiratory pause, which hardly exists on the sound side, is very obvious.

In voluntary breathing the differences are the same kind but exaggerated.

On coughing (c) the curves move in opposite directions, for a while on the sound side after somewhat exaggerated inspiration the chest contracts, the paralyzed side instead of contracting it is distended by the coughing, and the more powerful the cough the greater the distention or bulging."

West, Samuel. $Q J$ Med 1907-08;1:448-53.

RT ROSS

\section{Diphtheritic paralysis}

"There seems then to be a two-fold mechanism in the production of diphtheritic paralysis in man. There is the initial sometimes severe and relatively short-lived "local" paralysis, due to the action of the toxin, which has ascended the nerve innervating the local lesion, on the nerve nuclei in the brainstem. Secondly, there is the later, longer lasting "generalised" paralysis which is part of the general systemic toxaemia."

Walshe, FMR. On the Pathogenesis of Diphtheritic Paralysis. Q J Med 1918;11:191-204.

RT ROSS

\section{Thromboangitis obliterans}

"In regard to the possible contributory influence of cigarette-smoking in this disease, I wish to emphasize that I have never come across an instance of the disease in a woman, nor yet in a man who is not, or has not been, a free cigarette smoker. Moreover, my observations and enquiries make certain that the women of the Jewish families in the East End of London are practically all absolute abstainers from tobacco. Smoking amongst these women is unknown and unheard of, though their menfolk are so notoriously fond of it."

Parkes-Weber, F. Thromboangiitis obliterans (non-syphilitic arteritis obliterans of Hebrews). $Q J$ Med 1916;36:289-300. 